\title{
On Consumer Perceived Value of Digital Cameras' Brands:A Survey from Beijing Market
}

\author{
Chen Xinhui ${ }^{\mathrm{a}}$, Duan Hang ${ }^{\mathrm{b}}$ \\ School of Economic and Management \\ North China University of Technology \\ Beijing, China \\ achenxh@ncut.edu.cn; ${ }^{\text {a } 595532284 @ q q . c o m ~}$
}

\author{
Jin Xin \\ Department of business and sales \\ Beijing Satellite Manufactory \\ Beijing, China \\ 55618975@qq.com
}

\begin{abstract}
This paper analyzes the concept of perceived value, and designs a scale of perceived value for brand digital cameras. Researchers used scale to measure importance degree of the four aspects of the perceived value of digital cameras with a certain brand, that is functional value, emotional value, economic value and social value, and then a comparative analysis is implemented between national and foreign brands. From the analysis of results, there is a significant relationship between costume's partial demographic statistic variables with the importance of four aspects of perceived value. The difference of perceived value between national and foreign brands is mostly reflected in functional value and social value. The most efficient way to improve national brand digital camera's competitiveness is to develop core techniques independently and build up the dominance of national brand.
\end{abstract}

Keywords-Digital Cameras; Perceived Value; National Brand; Questionnaire; Analysis of Variance (ANOVA)

\section{INTRODUCTION}

Compared to traditional cameras, the digital camera has advantages in image information's conversion, storage and transmission. Therefore consumers are more willing to choose the former one. In 2013, the sales volume of domestic digital cameras was 46.83 million units, and the total sale was almost 20 billion. While the sales volume of traditional camera in 2014 kept the same with the sales in 2013. After the five months in 2015 , the output of digital camera market had achieved 7,879,788 units ${ }^{[1]}$. Looking from the pixel, 16 million pixels is the focus of most concern, with growth rate of $50.3 \%$, however, more and more people began to pay attention to the digital cameras with above 20 million pixels, and the rate has reached $41.7 \%{ }^{[2]}$. At present, digital cameras are also used in very wide field, including multimedia presentations, video production, intelligence and news gathering, CAD-aided design, image data management, network communications, insurance, real estate industry, the medical records, geographical research, the printing industry, daily life etc. With the rapid expansion of the digital camera market, the status of digital Camera has stood out among digital products, even among IT market. According to the forecast of experts, China's digital camera market will continue to grow rapidly for the next five years.

Although the digital cameras will not completely replace the traditional camera in a short time, the market prospects of the digital camera have drawn many businesses attention. In recent years, foreign brands of digital cameras have excellent performance, full range of products and a competitive price, so the Chinese market is quickly occupied, accounting more than ninety percent of Chinese market. By contrast, the brand digital camera market has been squeezed and market living space is narrow, there are several aspects of reason for those dilemmas, such as lack of core technology and price advantage etc. ${ }^{[3]}$.

This paper analyzed the differences between domestic and foreign brands of digital cameras at the perspective of consumers' perceived value, especially pay attention to the differences between the different sub-groups, trying to clear the marketing striving directions of the national brand digital cameras manufacturers.

\section{LITERATURE REVIEW}

No matter in which ages, there are many scholars consider that consumers' perceived value has important meaning for every manufacturers and retails. (Vantrappen, 1992; Wwoodruff, 1997; Forester, 1999) ${ }^{[4]}$.Hartnett (1998) deemed that retailers met customer demand was the way to deliver the value to them, only the customer value could maintain their advantage in competition in the long time. Woodruff (1997) also considered that, if the retail customers were value-driven, operators must understand the customer value and grasp their focus to obtain competitive advantage. He believed that the consumer perceived value was same to the product attributes to certain product or service, whose performance and the using to promote or block custom to reach goal in certain situation would affect the preference and evaluation of application results ${ }^{[5]}$.Myoung Kyu Choi pointed that the perceived value had great influence on satisfaction and performance, the more value custom perceived, the better behavior performed ${ }^{[6]}$.

In the fact, the conception of consumer perceived value has not yet formed. Zeithaml (1988) believed that consumers' perceived value was the assessment of the effectiveness after consumers weigh the benefits that he can obtain from product or service with the cost he paid for. Foreign scholars like Parasuraman, Zaithaml and Berry(PZB), they developed the service perceived value scale named SERVQUAL in 1988, it measured the level of consumers' perception and expectations for services 
provided by particular business from tangibles, reliability, responsiveness, assurance, empathy, then compared and analyzed differences between consumers expectations and actual perceived, with those to define the value of the consumer. The greater the difference there is, the smaller the value of consumer perception ${ }^{[7-8]}$. The utility perspective or the rational aspect of consumers' perceived value which emphasizes the trade-off between the benefits and sacrifices has traditionally been prevalent among academics and marketers ${ }^{[9]}$.

Sheth, Newman and Gross (1991) developed a more theoretical framework of perceived value. They suggested that the perceived value is divided into five dimensions, namely, sociability, emotion, function, cognition and condition. Chinese scholars Wang Xingu (2005) considered that, from the perspective of utility theory of value, consumer value as a consumer perceived utility value should include economic value, functional value and psychological value. The so-called economic value is the value of cost savings for consumers in the same function; function Value is the value obtained from the product functions; psychological value refers to the psychological satisfaction of consumers ${ }^{[10]}$. In this paper, based on existing scale structure, it develops the measurement table for the second time for the characteristics of the digital camera industry, in order to measure consumer perception value of the brand digital cameras.

\section{RESEARCH METHODS AND DESIGN}

\section{A. Research Framework}

Based on the above literature analysis, the establishment of consumer perceived value scale in this paper is quoted Jillian C.Sweeney and Geoffrey N.Soutar' (2001) views. Measure the consumer perceived value from the functional value, emotional value, economic value and sociability ${ }^{[11]}$. Researchers focus on the following two points: (1) Analyzed weights and dimensions of customer perceived value of a digital camera, and the differences between different groups;(2)Analyze the difference in perceived value of mainstream brands of digital cameras in Beijing market.

In this paper, researchers use SPSS10.0 software to process survey data, and variable differentiated analysis methods is ANOVA

\section{B. Questionnaire designs}

Researchers designed this survey questionnaire based on referring to the relevant foreign customers perceived value scale and combining with features of digital camera product. To specific design, the consumer perceived value scale designed the 14 questions from four dimensions, "Value", "sentimental value", "economic value" and "social value"( Q201 Q214). Respondents though filling out a Likert7 grade scale to complete the answer, The higher the figure, the greater degree of recognition; Then, there are 12 items to measure the importance of perceived value( Q301 Q312); Measurement scales also used Likert7 grade scale, 7 represents the highest level of importance while 1 represents the lowest level. Researchers also have 5 question to Describe the demographics of respondents (Q401 Q405).For details, see questionnaire in Appendix.
In order to check the reliability of scale and whether consumers correctly understand the meaning of the problem researchers pre-tested questionnaire in the residential area near the campus. Therefore, researchers issued 50 questionnaires which actually recovered 38.Then researchers do feasibility analysis of survey data, the result is that functional value, sentimental value, reliability economic value and social value each is $0.901,0.883$, 0.734 and 0.721 , all above 0.70 , which proves the questionnaire in this study has a higher reliability. At the same time, according to the problems showing in the test, researchers make some modifications to the questionnaire.

\section{Sample selection and data collection}

The main respondents of this research are those people who have a certain brand of digital cameras or who are familiar with one brand of digital cameras. In order to ensure that the respondents of the investigation has broadly representative, researchers chose three different types of research points, the nearby residential areas, electrical store and universities, and take the way of random intercept, voluntary answer. Researchers divided research team into three groups, one located in the residential neighborhood, one located near high school, another located in the vicinity of electrical store, and researchers request research team before questionnaires researchers should ask respondents whether they are familiar with certain brands of digital cameras, if the answer is yes, sent out questionnaires. Fill in the questionnaire in anonymously way, on the spot sent and recover.500 questionnaires totally, with 463 valid questionnaires.

Among those respondents, there are 227 males and 236 females, accounting for $49.0 \%$ and $51 \%$ of all respondents. Most respondents were distributed between age 30 to 50 years old, accounting for $58.1 \%$.Under college accounted for $7.1 \%$, college accounting for $32.8 \%$, undergraduate and above accounted for $60.1 \%$.Judging from the monthly income, wage in 2000 Yuan or less account for 27.2\%, 2,001 Yuan to 4,000 Yuan account for 51.2 percent,4001 to 8000 Yuan account for 19.0 percent; more than 8000 Yuan, accounting for 2.6\%.the most common channels for respondents to obtain digital camera brand information is introduced by friends, Secondly is getting information from internet and professional journals. On average, they use 2.3 channels to get information about digital camera brands. Comparing with the relevant population data in 2006 Beijing Statistical Yearbook, sample's distribution is in line with demographics of Beijing. Specifically as shown in Table I :

TABLE I. SAMPLE CHARACTERISTICS

\begin{tabular}{|l|l|c|c|}
\hline \multicolumn{2}{|c|}{ Classification } & number & percentage \\
\hline \multirow{3}{*}{ Gender } & Male & 227 & 49.0 \\
& Female & 236 & 51.0 \\
& Total & 463 & 100.0 \\
\hline \multirow{4}{*}{ Age (year) } & $20-$ & 52 & 11.2 \\
& $20-30$ & 98 & 21.2 \\
& $31-50$ & 369 & 58.1 \\
& $50+$ & 44 & 9.5 \\
& Total & 463 & 100.0 \\
\hline
\end{tabular}




\begin{tabular}{|l|l|c|c|}
\hline & High school- & 33 & 7.1 \\
& College & 152 & 32.8 \\
& Bachelor & 223 & 48.2 \\
& Graduate+ & 55 & 11.9 \\
& Total & 463 & 100.0 \\
\hline \multirow{4}{*}{ Monthly } & $2000-$ & 126 & 27.2 \\
income & $2001-4000$ & 237 & 51.2 \\
(Unit:Yuan) & $4001-8000$ & 88 & 19.0 \\
& $8000+$ & 12 & 2.6 \\
& Total & 463 & 100.0 \\
\hline \multirow{3}{*}{ Information } & Friends & 342 & 31.8 \\
Sources & Internet & 275 & 25.6 \\
(Mul tiple & Magazine & 207 & 19.3 \\
choices) & Television & 152 & 14.2 \\
& Other & 98 & 9.1 \\
& Total & 1074 & 100.0 \\
\hline
\end{tabular}

In the research, researchers related to the brand of Panasonic, Sony, Canon, Kodak, Patriot and other 10 wellknown brands.

While a certain brand of digital cameras has the number of product types that researchers didn't make a specific distinction. Therefore, there is an implicit assumption: The same brands of digital cameras have a similar consumer perceived value without significant difference.

\section{DATA ANALYSIS AND DISCUSSION}

\section{A. Analysis of the importance of dimension of consumer perceived value}

Researchers can see from Table II that the most important factor is the functional value whose average score is 5.62 and standard deviation is 1.11 , which shows that not only the functional value is important but consumers have same views on this. Then emotional value and social value whose average score is 4.60 and 4.80. However, the standard deviation of emotional value is the highest, which show big discrete views of consumers. And finally is economic value. Therefore, the importances of perceived value dimensions of the brand digital camera are functional value (FV), sociability value (SV), emotional value (EMV) and economic value (EV).

TABLE II. IMPORTANCE OF CONSUMER PERCEIVED VALUE DIMENSIONS

\begin{tabular}{|l|c|c|c|}
\hline $\begin{array}{c}\text { Value } \\
\text { dimensions }\end{array}$ & Means & $\begin{array}{c}\text { Std. } \\
\text { deviation }\end{array}$ & \begin{tabular}{c} 
calculations \\
\hline $\begin{array}{l}\text { Functional } \\
\text { value(FV) }\end{array}$
\end{tabular} \\
\hline $\begin{array}{l}\text { Emotional } \\
\text { value(EMV) }\end{array}$ & 4.62 & 11.1 & $\begin{array}{c}(\mathrm{Q} 301+\mathrm{Q} 302+\mathrm{Q} 303+ \\
\mathrm{Q} 304) / 4\end{array}$ \\
\hline $\begin{array}{l}\text { Economic } \\
\text { value(EV) }\end{array}$ & 4.20 & 12.1 & $\begin{array}{c}(\mathrm{Q} 307+\mathrm{Q} 308+\mathrm{Q} 30 \\
9+\mathrm{Q} 310) / 4\end{array}$ \\
\hline $\begin{array}{l}\text { Sociability } \\
\text { value(SV) }\end{array}$ & 4.80 & 12.6 & $\mathrm{Q} 311$ \\
\hline
\end{tabular}

B. Analysis of different importance between consumer groups' perceived value dimension

Before the statistical analysis, researchers do the normality test, the results show that the data conforms to normal distribution; and then researchers do the homogeneity test of variance. Because of space limitations, the non-critical results won't be presented here. Statistical analysis are shown in table III, researchers can find that there is a significant difference in judging importance of economic value for different gender $(\mathrm{P}<0.05)$. Researchers continue to analyze their average score can find that men focus more on economic values than women. This may because male consumers more rational and more sensitive to economic expenditure. But gender doesn't impact obviously on importance of other three dimensions.

TABLE III. THE INFLUENCE THE GENDER HAS ON IMPORTANCE OF PERCEIVED VALUE

\begin{tabular}{|c|c|c|c|c|c|}
\hline \multicolumn{2}{|c|}{ Items } & FV & EMV & EV & SV \\
\hline \multirow{2}{*}{ Gender } & Male(227) & 5.22 & 4.51 & 4.80 & 4.72 \\
\cline { 2 - 6 } & Female(236) & 5.33 & 4.70 & 4.24 & 4.66 \\
\hline $\begin{array}{c}\text { Statistical } \\
\text { test }\end{array}$ & T values & 0.28 & 0.49 & 1.92 & 0.06 \\
\cline { 2 - 6 } & P values & 0.63 & 0.48 & $0.03 * *$ & 0.81 \\
\hline *The number in parentheses is samples.
\end{tabular}

*The number in parentheses is samples.

From table IV, researchers can find that consumers with different income have significant differences in judging the importance of emotional value judgment, economic value and sociability value $(\mathrm{P}<0.05)$. Continuing to analyze their average researchers can discover that consumer groups with monthly income below 2,000 Yuan think economic value is most important. They have an average of 5.29, much higher than the other groups; Consumer groups with income in 2001 4000 Yuan believe functional value is the most important, but didn' $t$ higher than other groups significantly, this shows that all consumer groups have attached great importance to functional value of digital cameras; High-income groups with 4001 8000 considered most important into emotional values, they have an average of 5.91, much higher than the other groups. High-income consumer groups with more than 8000 Yuan believe that the most important is sociability value; they have an average of 6.77 higher than others. These results indicate that there are obvious differences of every consumer groups' demands of digital camera.

TABLE IV. EFFECT OF IMPORTANCE OF PERCEIVED VALUE DIMENSION

\begin{tabular}{|c|l|c|c|c|c|}
\hline \multicolumn{2}{|c|}{ Items } & FV & EMV & EV & SV \\
\hline \multirow{3}{*}{$\begin{array}{c}\text { Monthly } \\
\text { income } \\
\text { (Yuan) }\end{array}$} & $2000-(126)$ & 5.18 & 4.45 & 5.29 & 4.47 \\
\cline { 2 - 6 } & $2001 \sim 4000(237)$ & 5.77 & 4.96 & 4.93 & 4.70 \\
\cline { 2 - 6 } & $4001 \sim 8000(88)$ & 5.52 & 5.91 & 4.32 & 5.06 \\
\cline { 2 - 6 } & $8000+(12)$ & 5.28 & 3.50 & 1.98 & 6.77 \\
\hline $\begin{array}{c}\text { Statistical } \\
\text { test }\end{array}$ & T values & 1.06 & 4.35 & 6.62 & 3.40 \\
\cline { 2 - 6 } & P values & 0.37 & 0.01 & 0.00 & 0.02 \\
\hline
\end{tabular}

From Table V, researchers can find that consumers of different ages have significant differences in judging emotional value and sociability value $(\mathrm{P}<0.05)$. Further analyze their average researchers can find 50 years old or older consumer group puts more emphasis on emotional values than other groups; Consumer group with 30-50 years old put more emphasis on sociability than other groups'. However, there were no significant differences of 
judging the importance between the functional values and economic value.

TABLE V. THE IMPACT OF AGE ON THE IMPORTANCE OF PERCEIVED VALUE DIMENSION

\begin{tabular}{|c|l|c|c|c|l|}
\hline \multicolumn{2}{|c|}{ Items } & FV & EMV & EV & SV \\
\hline \multirow{4}{*}{$\begin{array}{c}\text { Age (Unit: } \\
\text { Year) }\end{array}$} & $20-(52)$ & 5.43 & 4.88 & 4.41 & 4.24 \\
\cline { 2 - 6 } & $21 \sim 30(98)$ & 5.31 & 4.62 & 4.32 & 4.83 \\
\cline { 2 - 6 } & $31 \sim 50(369)$ & 5.39 & 4.75 & 4.34 & 5.69 \\
\cline { 2 - 6 } & $50+(44)$ & 5.64 & 5.60 & 4.96 & 4.60 \\
\hline $\begin{array}{c}\text { Statistical } \\
\text { test }\end{array}$ & T values & 0.48 & 1.93 & 0.31 & 1.83 \\
\cline { 2 - 6 } & P values & 0.69 & 0.03 & 0.82 & 0.05 \\
\hline \multirow{2}{*}{ The number in parentheses is samples. } & \multicolumn{4}{|l}{} \\
\cline { 2 - 6 }
\end{tabular}

\section{Difference analyzing of Perceived value of different brand digital cameras}

As can be seen from Table VI, According to the sequence of the average economic value, the top three brands are Canon, Nikon and cable Nigeria. While domestic brands Patriots ranked fourth, Lenovo came in sixth place; According to the sequence of the average functional value, The top three brands are Sony, Panasonic and Fuji, Patriots ranked eighth, Lenovo ranked tenth; According to the sequence of the average emotional values, the top three are Sony, Casio, Canon and Panasonic tied for third, Patriots ranked tenth, Lenovo ranked eighth; According to the sequence of sociability value score, the top three brands are Sony, Olympus division, and Matsushita; Patriots and Lenovo respectively ranked ninth and tenth position.

TABLE VI. DIFFERENT BRANDS OF DIGITAL CAMERAS PERCEIVED VALUE MEASUREMENTS

\begin{tabular}{|c|c|c|c|c|c|c|c|c|c|}
\hline \multirow{2}{*}{ Brands } & \multicolumn{2}{|c|}{$\mathrm{FV}$} & \multicolumn{2}{|c|}{ EMV } & \multicolumn{2}{|c|}{ EV } & \multicolumn{2}{|c|}{ SV } & \multirow[t]{2}{*}{$\begin{array}{l}\text { Measurement Scale } \\
\text { Description }\end{array}$} \\
\hline & Mean & $\begin{array}{c}\text { Std. } \\
\text { deviation }\end{array}$ & Mean & $\begin{array}{c}\text { Std. } \\
\text { deviation }\end{array}$ & Mean & $\begin{array}{c}\text { Std. } \\
\text { deviation }\end{array}$ & Mean & $\begin{array}{c}\text { Std. } \\
\text { deviation }\end{array}$ & \\
\hline Sony(103) & 4.76 & 0.89 & 5.66 & 0.98 & 5.33 & 1.16 & 5.84 & 1.53 & function \\
\hline Canon(82) & 4.81 & 0.93 & 5.47 & 1.01 & 5.07 & 1.17 & 5.53 & 1.42 & value:Q201 Q204 \\
\hline Kodak(57) & 4.64 & 0.86 & 5.24 & 0.89 & 4.82 & 0.89 & 4.87 & 1.33 & There are 2 about \\
\hline Olympus(62) & 4.74 & 0.85 & 5.45 & 1.02 & 4.98 & 1.13 & 5.62 & 1.23 & value:Q205 Q206 \\
\hline Nikon(53) & 4.78 & 0.81 & 5.41 & 1.03 & 5.00 & 1.04 & 4.88 & 0.75 & There are 6 about \\
\hline Fuji(36) & 4.69 & 0.75 & 5.51 & 0.96 & 4.90 & 1.13 & 5.51 & 1.16 & economic \\
\hline Casio(21) & 4.59 & 1.08 & 5.32 & 1.10 & 5.16 & 1.22 & 5.29 & 1.42 & $\begin{array}{c}\text { value:Q207 Q212 } \\
\text { There are 2about }\end{array}$ \\
\hline Panasonic(17) & 4.51 & 0.73 & 5.88 & 1.02 & 5.06 & 1.24 & 5.60 & 1.48 & sociability \\
\hline Lenovo(18) & 4.66 & 0.88 & 4.81 & 0.97 & 4.85 & 1.29 & 4.60 & 1.31 & value:Q213 Q214 \\
\hline Aigo(14) & 4.72 & 0.82 & 5.12 & 1.07 & 4.76 & 0.98 & 4.80 & 1.43 & \\
\hline
\end{tabular}

But from the analysis of Standard deviation size, the Standard of Economic values and functional values is less. This shows that consumers perceiving with above brands of digital cameras on the Two value dimensions are Consistent, sort results have higher reliability; On the contrary, standard deviation size of Emotional value and sociability value is more larger, his shows that consumers perceiving on both dimensions is weaker, sort Results have weaker reliability, it is needed to research further.

Therefore, researchers focus on each of the subitems which constitute economic value and functional value dimension, through careful comparative study found, domestic brands compared with foreign brands, the maximum differences are in the photo quality and camera function, Patriots and Lenovo have respectively ranked eighth, tenth and ninth, eighth. But in two subitems of replace battery prices and camera power consumption, Lenovo and the Patriots were ranked in Midstream. Even in the aftermarket warranty sub key, Patriots and Lenovo respectively occupy the top two; But In camera prices sub key Patriots and Lenovo were respectively ranked in the second and fourth. The overall strength of the strongest brands are Sony, although the function of Panasonic more outstanding, but it is not economic; Fuji camera has more powerful function and more economical but its design and service attitude came in the last one. These results provide direction for the business to enhance the consumer's perceived value and the competition of brand.

\section{CONCLUSIONS AND LIMITATIONS}

This paper systematically analyzes the connotation of consumer perceived value, through conducting a survey on popular brands of digital cameras in Beijing market; researchers solve two basic problems in the initial design of the research framework. By the results of the survey statistics, at first, researchers found that consumers to buy different brands of digital cameras, they considered that the most important value is functional value, followed by sociability value and emotional value, and finally is the economic value. Men pay more attention to economic values than women; High-income groups agree on sociability value is significantly higher than other groups; Older age groups agree on the emotional value is significantly higher than other groups. This is provides a theoretical basis for business owners to implement market segmentation. Operators should adopt different marketing strategies to meet the needs of different categories of customers, price competition strategy should be caution in the digital camera market competition, and the price following strategies should be the best choice for domestic brands. Next, by analyzing the differences between domestic brands and foreign brands, researchers found that 
compared with foreign brands, the biggest disadvantage of domestic brands is the lack of functional values reflecting, and advantage is long after-sales warranty and low battery prices. There are differences in consumer perception value of foreign brands also, which reflect market positioning competitive strategies of foreign brands on the other hand. At last, due to time and cost constraints, the scope of the investigation and number of samples are limited, so the brand perceived value especially for some brand with small sample, those reliability should be further verified.

\section{REFERENCES}

[1] Industry data(2015), "Digital camera production statistics of the provinces of first five months in 2015." industry network, http://www.chyxx.com.

[2] Zhongguancun online(2015), "Chinese digital camera market research report in 2014-2015." HeXun. www.http://tech.hexun.com.

[3] Li Z.X.(2006) "Problems of domestic digital camera market." video materials, 2004(6):30-32.

[4] Lv Q.H.(2005) "Talking about the customer value theory and its ideological basis." economic issues exploring,2005(9),pp.63-66.
[5] Wang X.Q. (2005). "Customer value and its evaluation method research.” Nankai management review. Vol.8,2005(5),pp.31-34.

[6] Myoung Kyu Choi and Kyeong Seok Han(2014). "A study on the service quality of SMEs management consulting affecting the perceived management performance in mobile communication environments." J Comput Virol Hack Tech, 2014(10):145-156.

[7] Parasuraman, A., \& Colby, C. L. (2001). Techno-ready marketing: How and why your customers adopt technology. Avenue of the Americas, NY: Free Press.

[8] Zeithaml, Valarie A. (1988). "Consumer Perceptions of Price, Quality and Value: A Means-End Mode 1 and Synthesis of Evidence." Journal of Marketing, 52 (7),pp.2-22.

[9] Kaili Yieh and Maggie Biwei Wei(2012). "The Effect of Techno;ogy Readiness on Customer Perceived Value: An Empirical Analysis." Institute of Information and Society,2012(33), pp. 177-183.

[10] Jillian C.Sweeney and Geoffrey N.Soutar (2001). "Consumer perceived value: The development of a multiple item scale, Journal of Retailing, 77.203-220.

[11] E Chang-His Yu and Gow-Liang Huang (2006). "A Study of Service Quality, Customer Satisfaction and Loyalty in Taiwanese Leisure Industry. " The journal of American Academy of Business, 9(1):126-132

\section{APPENDIX. Questionnaire}

1.You are most familiar with digital camera brand is

(Playing " $\sqrt{ }$ " in the appropriate “व")

$\square$ Sony $\square$ Canon $\square$ Kodak $\square$ Olympus $\square$ Nikon $\square$ Fuji $\square$ Casio $\square$ Lenovo $\square$ Aigo $\square$ Panasonic other (please specify)

2. According to your familiar brand-A products and personal experience, answer the following questions.

(1 to 7 show your level of agreement: 7 represents strong agree, 1 represents strong disagree)

\begin{tabular}{|c|c|c|c|c|c|c|c|}
\hline Q201.This brand of digital cameras can take high-quality photos & 1 & 2 & 3 & 4 & 5 & 6 & 7 \\
\hline Q202.This brand of digital camera has a stylish design & 1 & 2 & 3 & 4 & 5 & 6 & 7 \\
\hline Q203.This brand has a strong digital camera function & 1 & 2 & 3 & 4 & 5 & 6 & 7 \\
\hline Q204.This brand of digital camera operate simply and functional & 1 & 2 & 3 & 4 & 5 & 6 & 7 \\
\hline Q205.This brand is my favorite brand & 1 & 2 & 3 & 4 & 5 & 6 & 7 \\
\hline Q206.This brand of digital cameras have excellent service attitude: & 1 & 2 & 3 & 4 & 5 & 6 & 7 \\
\hline Q207.This brand of digital cameras have reasonably priced & 1 & 2 & 3 & 4 & 5 & 6 & 7 \\
\hline Q208.This brand of digital cameras are cost-effective & 1 & 2 & 3 & 4 & 5 & 6 & 7 \\
\hline Q209.This brand of digital cameras have a excellent value for money & 1 & 2 & 3 & 4 & 5 & 6 & 7 \\
\hline Q210.This brand of digital cameras' memory card/stick have a reasonable price & 1 & 2 & 3 & 4 & 5 & 6 & 7 \\
\hline Q211.This brand of digital cameras' batteries have reasonable prices & 1 & 2 & 3 & 4 & 5 & 6 & 7 \\
\hline Q212.This brand of digital cameras have a reasonable energy consumption standards & 1 & 2 & 3 & 4 & 5 & 6 & 7 \\
\hline Q213.This brand of digital cameras is very consistent with my identity & 1 & 2 & 3 & 4 & 5 & 6 & 7 \\
\hline Q214.This brand of digital cameras have been agreed with my colleague & 1 & 2 & 3 & 4 & 5 & 6 & 7 \\
\hline
\end{tabular}

3.Assuming that you are intending to buy or re-buy a digital camera, please give the relative importance of those various factors when you select products.(1 to 7 show the degree of importance: 7 represents a most important and 1 means most unimportant)

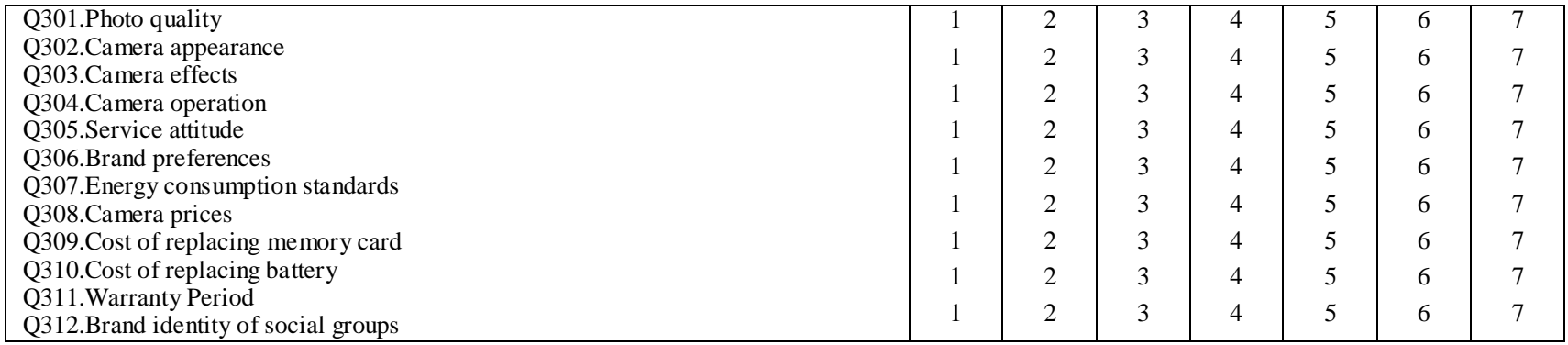

4.Please provide your simple personal information.(Playing " $\sqrt{ }$ " in the appropriate “ $\square$ ” )

Q401.Sex: $\quad \square$ Male $\quad \square$ Female

Q402.Age(Unit:Year): $\quad \square 20-\quad \square 20 \sim 30 \quad \square 31 \sim 50 \quad \square 50+$

Q403.The average monthly income(Unit:Yuan): $\quad \square$ 2000- $\quad \square$ 2001 4000 $\quad \square$ 4001 8000Yuan $\square 8000+$

Q404.Level of education: $\square$ High school- $\square$ college $\square$ Bachelor $\square$ Graduate+

Q405.The channel you get the information source about the brands of digital cameras:

$\square$ Professional Magazine $\quad \square$ Internet $\quad \square$ TV advertising $\quad \square$ Introduce by friends / relatives $\quad \square$ Other 